\title{
ALKALINE PHOSPHATASE IN THE REPRODUCTIVE SYSTEM OF THE HEN*
}

\author{
F. H. WILCOX AND W. S. CLOUD \\ Department of Poultry Science, University of Maryland, \\ College Park, Maryland, U.S.A.
}

(Received 30th December 1964)

\begin{abstract}
Summary. Alkaline phosphatase level was measured in parts of the reproductive system of laying White Leghorn females of a random bred control line and it was markedly higher in the ovary than in the oviduct, egg yolk, egg white and vitelline membrane. Within the ovary the highest levels were observed in the membranes of large follicles, whereas levels were very low in contents of these follicles. A line with a high level of phosphatase in blood serum did not differ from the random bred control line in the phosphatase level of ovarian follicle membrane or vitelline membrane. However, it had a significantly higher level of the enzyme in egg yolk and ovarian follicle contents, as well as in blood serum. The role of alkaline phosphatase in the functioning of the ovary is discussed.
\end{abstract}

\section{INTRODUCTION}

Evidence has been advanced (see Wilcox, Van Vleck \& Shaffner, 1962) for a positive relationship between alkaline phosphatase level in serum and egg production. A line selected for a high level of this enzyme laid eggs at a higher rate than the control line from which it originated. The present study is an attempt to elucidate the mechanism for this relationship by measurement of alkaline phosphatase level in various parts of the reproductive system of hens of the high phosphatase line and control line.

Alkaline phosphatase has been shown to be present in all regions of the oviduct by various workers (Auchinachie \& Emslie, 1934; Gutowska, Parkhurst, Parrot \& Verburg, 1943; Sanz \& Lorenzo, 1950; Brown \& Badman, 1962), although at rather low levels. Auchinachie \& Emslie (1934) and Gutowska et al. (1943) found somewhat higher levels of phosphatase in the small white ovules (immature white follicles) and the ovary than in the oviduct, but only a trace of the enzyme in the large ova. However, a high phosphatase level is present in the follicle membrane of large ova (Abe, Kaneko, Otsuka \& Hosoda, 1962). Alkaline phosphatase level has also been measured in eggs; small amounts were observed in the yolk, but none in the white (Thompson, 1944; Lineweaver, Morris, Kline \& Bean, 1948). In each of these studies

* Scientific Article No. A1170, Contribution No. 3645 of the Maryland Agricultural Experiment Station. 
alkaline phosphatase level was measured only in a few parts of the reproductive system by each investigator, and therefore comparisons between parts are difficult. In the present study, enzyme level was first measured in all major parts of the reproductive system and egg. Since the highest level was found in the ovary, the analysis was then extended to ovarian follicles of different sizes. In addition, the high phosphatase line was compared to the control line in the enzyme level in the second largest ovarian follicle, and in the yolk and vitelline membrane of eggs.

\section{METHODS}

Stock used was hatched from eggs laid by birds of the random bred White Leghorn line (control line) originally developed at Cornell University (King, Carson \& Doolittle, 1959) and of the fifth selected generation of the high phosphatase line (Wilcox, 1963). Lines were raised intermingled throughout. Pullets used for assays of the female reproductive system were 7 months of age; each one had a hard-shelled egg in its shell gland. Pullets used solely for assays of eggs were 12 months of age.

Conditions for preparing homogenates of organs and for alkaline phosphatase analysis were as previously described (Wilcox, 1963). Vitelline membranes were obtained by first separating the yolk from the white, then removing adhering chalazae and inner thick white by rolling the yolk on absorbant paper, and finally by breaking the yolk and washing it from the vitelline membrane with water. The membrane was then handled in the same way as the organs. Egg white was homogenized in a Waring blendor for 5 sec. Egg yolk and contents of ovarian follicles were mixed by gentle stirring and diluted with an equal volume of distilled water with plastic disposable syringes for greater ease of handling.

In experiments in which only eggs were used, they were analysed for alkaline phosphatase on the day they were laid. Those analysed for cholesterol, fat and total solids were boiled for 12 min on the day the egg was laid, the yolk was separated from the remainder of the egg and frozen at $-20^{\circ} \mathrm{C}$ until analysis. Yolk weights are for boiled yolks. Yolk lipids were extracted as described by Harris \& Wilcox (1963); an aliquot was analysed for cholesterol by the method of Zak (1957) and another aliquot was evaporated to dryness for fat determination.

\section{RESULTS}

Alkaline phosphatase level of various parts of the reproductive system of two hens of the control line is given in Table 1. Activity was relatively low in all parts of the oviduct and the egg yolk and absent in egg white. These data are in agreement with the literature. Enzyme level was high in all three parts of the ovary. Ovary tissue included the portion of ovary remaining after white ovules and larger follicles had been removed. White ovules ranged in size from 36 to $178 \mathrm{mg}$.

The level in the membrane of the largest ovarian follicle was considerably higher than the other two parts of the ovary. Therefore, enzyme activity was 
TABLE 1

ALKALINE PHOSPHATASE LEVEL OF OVARY AND OVIDUCT (GONTROL LINE)

\begin{tabular}{l|c|c}
\hline \multirow{2}{*}{ Component } & \multicolumn{2}{|c}{ Nitrophenol } \\
\cline { 2 - 3 } & Hen 1 & Hen 2 \\
\hline & $(\mathrm{mm} / \mathrm{kg} / \mathrm{hr})$ & $(\mathrm{mm} / \mathrm{kg} / \mathrm{hr})$ \\
Ovary tissue & 159 & 173 \\
White ovules & 389 & 363 \\
Membrane of largest ovarian follicle & 1958 & 1600 \\
Infundibulum & $6 \cdot 4$ & $12 \cdot 1$ \\
Magnum & $3 \cdot 2$ & $4 \cdot 7$ \\
Isthmus & $4 \cdot 1$ & $5 \cdot 6$ \\
Shell gland & $4 \cdot 8$ & $6 \cdot 2$ \\
Vagina & $9 \cdot 0$ & $14 \cdot 7$ \\
& $(\mathrm{~mm} / \mathrm{l} / \mathrm{hr})$ & $(\mathrm{mm} / \mathrm{l} / \mathrm{hr})$ \\
Egg white* & $0 \cdot 00$ & $0 \cdot 00$ \\
Egg yolk* & $1 \cdot 60$ & $3 \cdot 40$ \\
Blood serum & $13 \cdot 0$ & $18 \cdot 8$ \\
\hline
\end{tabular}

* From hard-shelled egg in shell gland.

TABLE 2

ALKALINE PHOSPHATASE LEVEL OF OVARIAN FOLLIGLES (CONTROL LINE)

\begin{tabular}{|c|c|c|c|c|c|}
\hline \multirow{2}{*}{ Component } & \multicolumn{5}{|c|}{ Nitrophenol } \\
\hline & Hen 3 & Hen 4 & Hen 5 & Hen 6 & Average \\
\hline $\begin{array}{l}\text { Follicle membranes } \\
\qquad \begin{array}{l}F_{1} \\
F_{2} \\
F_{3} \\
F_{4} \\
F_{5} \\
F_{7}\end{array} \\
\text { White ovule membranes } \\
\text { Vitelline membrane* }\end{array}$ & $\begin{array}{c}(\mathrm{mm} / \mathrm{kg} / \mathrm{hr}) \\
877 \\
1195 \\
1161 \\
899 \\
401 \\
11.2\end{array}$ & $\begin{array}{c}(\mathrm{mm} / \mathrm{kg} / \mathrm{hr}) \\
1359 \\
1617 \\
830 \\
1306 \\
\\
814 \\
43.7\end{array}$ & $\begin{array}{c}(\mathrm{mm} / \mathrm{kg} / \mathrm{hr}) \\
1220 \\
1274 \\
1273 \\
1135 \\
354 \\
24 \cdot 6\end{array}$ & $\begin{array}{c}(\mathrm{mm} / \mathrm{kg} / \mathrm{hr}) \\
800 \\
1387 \\
762 \\
337 \\
370 \\
30 \cdot 6\end{array}$ & $\begin{array}{c}(\mathrm{mm} / \mathrm{kg} / \mathrm{hr}) \\
1064 \\
1015\end{array}$ \\
\hline 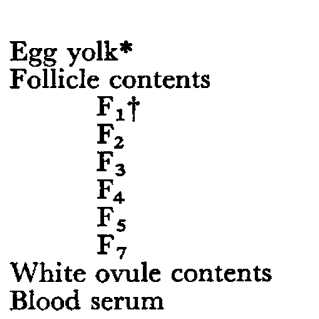 & $\begin{array}{c}(\mathrm{mm} / \mathrm{l} / \mathrm{hr}) \\
0.52 \\
\\
5.86 \\
0.98 \\
\\
0.65 \\
0.50 \\
1.81 \\
3.4\end{array}$ & $\begin{array}{r}(\mathrm{mm} / \mathrm{l} / \mathrm{hr}) \\
0.26 \\
\\
1.52 \\
0.88 \\
0.87 \\
1.04\end{array}$ & $\begin{array}{c}(\mathrm{mm} / \mathrm{l} / \mathrm{hr}) \\
0.28 \\
0.50 \\
\\
0.64 \\
\\
0.83 \\
0.57 \\
1.09 \\
2.6\end{array}$ & $\begin{array}{c}(\mathrm{mm} / \mathrm{l} / \mathrm{hr}) \\
0.62 \\
\\
0.64 \\
0.36 \\
0.25 \\
0.69 \\
\\
1.40 \\
3.2\end{array}$ & $\begin{array}{r}(\mathrm{mm} / \mathrm{l} / \mathrm{hr}) \\
0.42 \\
2.13 \\
0.69\end{array}$ \\
\hline $\begin{array}{l}\text { Kidney } \\
\text { Duodenum }\end{array}$ & $\begin{array}{c}(\mathrm{mm} / \mathrm{kg} / \mathrm{hr}) \\
615 \\
2360\end{array}$ & $\begin{array}{c}(\mathrm{mm} / \mathrm{kg} / \mathrm{hr}) \\
498 \\
3426\end{array}$ & $\begin{array}{c}(\mathrm{mM} / \mathrm{kg} / \mathrm{hr}) \\
468 \\
2814\end{array}$ & $\begin{array}{c}(\mathrm{mm} / \mathrm{kg} / \mathrm{hr}) \\
560 \\
3596\end{array}$ & $\begin{array}{c}(\mathrm{mm} / \mathrm{kg} / \mathrm{hr}) \\
535 \\
3049\end{array}$ \\
\hline
\end{tabular}

* From hard-shelled egg in shell gland.

$\dagger F_{1}=$ largest ovarian follicle, $F_{2}=$ second largest ovarian follicle, etc. 
measured in several ovarian follicles and follicle contents of four hens of the control line. Results are presented in Table 2. Alkaline phosphatase level was high in membranes of all of follicles $\left(F_{1}\right.$ to $\left.F_{7}\right)$; variation between follicles was considerable but apparently unrelated to follicle size. However, enzyme level was lower in the membranes of the white ovules than in larger follicles.

TABLE 3

AVERAGE ALKALINE PHOSPHATASE AGTIVITY OF SEVERAL ORGANS IN PRESENCE OF $0.01 \mathrm{M}$ SODIUM BORATE (CONTROL LINE)

\begin{tabular}{l|c}
\hline \multicolumn{1}{c|}{ Component } & $\begin{array}{c}\text { Residual alkaline } \\
\text { phosphatase activity } \\
(\% \text { of control })\end{array}$ \\
\hline Duodenum & 32 \\
Kidney & 88 \\
Serum & 89 \\
Ovarian follicle membrane $\left(\mathbf{F}_{1}\right)$ & 90 \\
Ovarian follicle contents $\left(\mathrm{F}_{1}\right)$ & 111 \\
\hline
\end{tabular}

TABLE 4

GHARAGTERISTICS OF THE SECOND LARGEST OVARIAN FOLLICLE OF A LINE SELECTED FOR HIGH SERUM ALKALINE PHOSPHATASE LEVEL VERSUS CONTROL LINE*

\begin{tabular}{l|c|c}
\hline & \multicolumn{2}{|c}{ Line } \\
\cline { 2 - 3 } & Control & High \\
\hline Alkaline phosphatase level (mM nitrophenol/hr) & & \\
$\quad$ Follicle membrane/kg & 1202 & 1168 \\
$\quad$ Follicle membrane/follicle & $0 \cdot 52$ & 0.49 \\
$\quad$ Follicle contents/1 & $0 \cdot 56$ & 1.84 \\
$\quad$ Blood serum/1 & 3.3 & 11.0 \\
Weights of follicle and membrane used for analysis & $11 \cdot 8$ & 10.8 \\
$\quad$ Follicle (g) & 435 & 421 \\
$\quad$ Follicle membrane (mg) & 43.0 & 34.5 \\
Weight of all follicles weighing 0.5 g or more, exclud. & 7.5 & 6.8 \\
$\quad$ ing largest follicle (g) & & \\
No. follicles weighing 0.5 g or more & \\
\hline
\end{tabular}

* Each figure an average based on fifteen birds, except eleven or twelve birds for bottom two rows.

Phosphatase level in the follicle contents was very low, although higher than in egg yolk. The level in the contents of the white ovules was higher than the contents of the large follicles with one exception $\left(F_{1}\right.$ of Hen 3$)$. It is of interest that the vitelline membrane possessed a greater concentration of alkaline phosphatase than the white or yolk.

Duodenum and kidney were analysed for comparative purposes. They were the organs which had the highest and second highest alkaline phosphatase levels respectively among a large number of organs previously studied in younger chickens of the same control line (Wilcox, 1963). The level in the 
duodenum was roughly three times that of the membrane of large ovarian follicles, which in turn had a level twice that of the kidney. Phosphatase activity was also measured in the presence of borate $(0.01 \mathrm{M})$ in the reaction mixture. Wilson \& Wilcox (1963) showed previously that the percentage of inhibition by borate is useful in distinguishing between phosphatase in duodenum and other organs (kidney, bone, liver). Results of such inhibition tests are given in Table 3 and are based on organs from the four hens represented in Table 2. Inhibition was much greater for duodenum than for kidney, as was found previously. Phosphatase of ovarian follicle contents and membrane resembled that of the kidney and serum.

Since the ovarian follicle had the highest phosphatase level of any part in the reproductive system, it was selected for comparisons of the high phosphatase

TABLE 5

ALKALINE PHOSPHATASE LEVEL IN YOLK AND VITELLINE MEMBRANE OF EGGS LAID BY HIGH PHOSPHATASE LINE AND CONTROL LINE*

\begin{tabular}{l|c|c}
\hline \multirow{2}{*}{ Component } & \multicolumn{2}{|c}{ Line } \\
\cline { 2 - 3 } & Control & High \\
\hline Egg weight $(\mathrm{g})$ & $59 \cdot 4$ & 61.9 \\
Alkaline phosphatase $(\mathrm{mm}$ nitrophenol $/ \mathrm{hr})$ & & \\
$\quad$ Vitelline membrane/membrane $\left(\times 10^{-4}\right)$ & $2 \cdot 83$ & 2.87 \\
Yolk/l & 0.51 & 1.05 \\
\hline
\end{tabular}

* Each figure an average based on thirty eggs/line.

line with the control line. Results are given in Table 4. No significant differences were observed between lines in the enzyme level in the follicle membrane, whether expressed on a basis of concentration per unit weight or per follicle. However, the high line had significantly higher level of phosphatase in follicle contents and serum $(P<0.01)$ than the control line. The lines showed no significant difference in weight of follicle or follicle membrane used for phosphatase analysis. Total weight and number of large follicles per hen (excluding the largest one) were somewhat less in the high line than the control line; both differences approached significance $(P<0 \cdot 10)$.

A rather interesting difference was observed in the birds used for comparisons of lines. Four out of twelve birds of the high line had a yolk in the upper magnum in addition to a hard-shelled egg in the shell gland; some albumen had been deposited on two of these yolks. None of the twelve birds of the control line had a yolk in the magnum, although ovulation had occurred in one. This prompted a further comparison of the two lines. The time was estimated between oviposition of one egg and detection of the egg to be laid on the following day by digital palpation. The averages for the two lines were nearly identical: $202 \mathrm{~min}$ for forty birds of the control line and $199 \mathrm{~min}$ for thirty-one birds of the high line. Thus the higher egg production of the high line compared to the control line is apparently not due to earlier ovulation, shorter time spent between ovulation and engulfment by the infundibulum, or shorter time in the magnum and isthmus. 
In a separate study the phosphatase level was measured in the yolk and vitelline membrane of newly laid eggs (Table 5). Level in vitelline membrane was expressed on a 'membrane' basis because of the difficulty of achieving uniform removal of water from the membrane. The lines did not differ significantly in amount of enzyme in vitelline membrane; egg weight was slightly higher in the high line $(P<0 \cdot 10)$. Enzyme level in yolk was significantly higher in the high line $(P<0.01)$.

TABLE 6

COMPOSITION OF YOLK OF EGGS LAID BY HENS OF A LINE SELECTED FOR HIGH SERUM ALKALINE PHOSPHATASE LEVEL VERSUS CONTROL LINE*

\begin{tabular}{l|c|c}
\hline \multirow{2}{*}{ Measurement } & \multicolumn{2}{|c}{ Line } \\
\cline { 2 - 3 } & Control & High \\
\hline Egg wt (g) & $59 \cdot 2$ & $60 \cdot 7$ \\
Yolk wt (g) & $19 \cdot 8$ & $18 \cdot 8$ \\
Yolk & & \\
Total solids (\%) & $47 \cdot 8$ & $47 \cdot 7$ \\
Fat (\%) & $35 \cdot 2$ & $34 \cdot 8$ \\
Cholesterol (mg/g yolk) & $30 \cdot 9$ & $30 \cdot 5$ \\
\hline
\end{tabular}

* Each figure an average based on thirty eggs/line.

The high level of alkaline phosphatase in the membrane of ovarian follicles suggested an involvement of the enzyme in secretion or transport of fat or protein into the follicle during its growth. Alkaline phosphatase is known to be involved in fat transport in the intestine. Yolks of eggs from the high line and control line were analysed for fat, cholesterol and total solids, since any differences in the functioning of the ovarian follicle of the two lines might conceivably be reflected in composition of the yolk. The results, as shown in Table 6, were negative; the only significant difference between lines was a lower yolk weight of the high line $(P<0 \cdot 05)$.

\section{DISCUSSION}

The high level of alkaline phosphatase in the ovary, particularly the membrane of the ovarian follicle, suggests that this enzyme plays an active role in the functioning of the ovary. The most likely explanation would be an involvement in transport of yolk material from the blood to the interior of the follicle. Abe et al. (1962) showed histochemically that the alkaline phosphatase in the ovarian follicle was confined to the theca interna, an area that is highly vascular (van Tienhoven, 1959). The small amount of phosphatase found in the contents of the ovarian follicle presumably originates either from blood or the follicle membrane. Its presence might be analogous to the appearance of phosphatase of duodenal origin in the lymph and blood during absorption of fat by the intestine of rats (Flock \& Bollman, 1948; Flock \& Bollman, 1950). It is noteworthy that the placenta of mammals also contains a high level of phosphatase 
(Anagnostopoulos \& Matsudaira, 1958) especially since this organ and the ovarian follicle membrane fulfil similar functions in fat transport from the maternal circulation.

The presence of alkaline phosphatase in the vitelline membrane has not previously been observed. The level of the enzyme was considerably greater than in the yolk. Alkaline phosphatase in the vitelline membrane might also be involved in passage of yolk material into the fluid portion of the ovarian follicle during growth of ova. Permeability of the vitelline membrane has been shown to change three times during this period (Romanoff \& Romanoff, 1949).

The mechanism responsible for the relationship between serum alkaline phosphatase and egg production remains obscure. No differences were observed between the high line and control line in phosphatase level in the follicle membrane or in amount of fat, cholesterol and total solids in yolk. It is possible that the relationship is due to a more rapid growth of ova in the high line which is not reflected in differences in these measurements. The relationship could also be due to differences in the digestive system. The additional phosphatase in serum of the high line is probably of duodenal origin (Wilson \& Wilcox, 1963). Moreover, on a high fat diet the serum phosphatase level is increased considerably more in the high line than the control line.

A difference between lines was found, however, in level of alkaline phosphatase in contents of the ovarian follicle and of egg yolk. If the enzyme in yolk originates in blood, this difference may merely be a reflection of the line differences in its level in serum.

\section{REFERENGES}

Abe, T., Kaneko, T., Otsuka, J. \& Hosoda, T. (1962) Changes in phosphatase activities of follicular membranes of growing follicles and atretic follicles in the laying hen and the starving hen. Poult. Sci. 41, 1447.

Anagnostopoulos, C. \& Matsudaira, H. (1958) Purification and kinetic studies of the alkaline phosphatase of human placenta. Proc. int. Symp. Enzyme Chem., Tokyo-Kyoto, 166.

Auchinache, D. W. \& Emslie, A. R. G. (1934) The significance of phosphatase estimations in the adult fowl. Biochem. 7. 28, 1993.

Brown, W. O. \& Badman, H. G. (1962) The respiration rate and alkaline phosphatase activity of the regions of the avian oviduct. Poult. Sci. 41, 654 .

Flock, E. V. \& Bollman, J. L. (1948) Alkaline phosphatase in the intestinal lymph of the rat. $\mathcal{F}$. biol. Chem. 175, 439.

Flock, E. V. \& Bollman, J. L. (1950) The influence of bile on the alkaline phosphatase activity of intestinal lymph. 7. biol. Chem. 184, 523.

Gutowska, M. S., Parkhurst, R. T., Parrot, E. M. \& Verburg, R. M. (1943) Alkaline phosphatase and egg formation. Poult. Sci. 22, 195.

Harris, P. C. \& Wilcox, F. H. (1963) Studies on egg yolk cholesterol. 1. Genetic variation and some phenotypic correlations in a random bred population. Poult. Sci. 42, 178.

King, S. C., Carson, J. R. \& Doolittle, D. P. (1959) The Connecticut and Cornell random-bred populations of chickens. World's Poult. Sci. F. 15, 139.

Lineweaver, H., Morris, H. J., Kline, L. \& Bean, R. S. (1948) Enzymes of fresh hen eggs. Arch. Biochem. 16, 443.

Romanoff, A. L. \& Romanoff, A. J. (1949) The avian egg. Wiley, New York.

Sanz, F. \& Lorenzo, P. L. (1950) La fosfatasa acida del oviducto de las aves. An. Fac. Vet. Univ. Madr. $2,45$.

Thompson, W. L. (1944) A study of the proteolytic enzyme activity in hen's eggs. Bull. Univ. Pittsburg, $40,311$.

VAN TIEnhoven, A. (1959) Reproduction in the domestic fowl: physiology of the female. Reproduction in Domestic Animals, Vol. II. Eds. H. H. Cole and P. T. Cupps. Academic Press, New York. 
WrLcox, F. H. (1963) Genetic control of serum alkaline phosphatase in the chicken. F. exp. Zool. 152, 195.

Wilcox, F. H., van Vleck, L. D. \& Shaffner, C. S. (1962) Serum alkaline phosphatase and egg production. Proc. XII World's Poultry Congr., Sydney, 19.

WrLson, H. R. \& WrLcox, F. H. (1963) Origin of an increased serum alkaline phosphatase in chicks. Proc. Soc. exp. Biol. Med. 113, 413.

ZAK, B. (1957) Simple rapid microtechnic for serum total cholesterol. Am. F. clin. Path. 27, 583. 